\title{
Ergonomia e Acessibilidade - Um Estudo de Caso Sobre os Problemas Potenciais na Concepção de Sistema de Locomoção Para Atividades Diárias na Cidade de Manaus
}

Ergonomics and Accessibility - A Case Study About Potential Problems in the Design of Locomotion System for Daily Activities in Manaus

\section{SANTOS, Erik Silva dos I Mestrando em Design}

Universidade Federal de Santa Catarina - UFSC

dossantos.erik@gmail.com

\section{Resumo}

O presente artigo busca apresentar o resumo de dados e informações adquiridos a partir de uma apreciação ergonômica (MORAES; MONT'ALVÃO, 2003), tendo enfoque nos usuários de cadeira de rodas que utilizam a mesma em áreas comuns da cidade de Manaus para as suas atividades diárias - o estudo busca apresentar sugestões preliminares cabíveis a projetação de um novo sistema-produto, que possibilitem a redução de constrangimentos causados às pessoas portadores de necessidades especiais.

Palavras-Chave: Ergodesign. Atividades diárias. Cidade. Deficiência física.

\section{Abstract}

This article seeks to present the resume of data and information acquired from an ergonomic assessment (MORAES; MONT'ALVÃO, 2003), with focus on wheelchair users who use the same areas in the city of Manaus for your daily activities - the study aims to provide preliminary suggestions applicable to projecting a new-product system, enabling the reduction of constraints caused to people with special needs.

Key-words: Ergodesign. Daily activities. City. Physical disability. 


\section{INTRODUC̣̃̃O}

Segundo estatísticas, $14,5 \%$ da população brasileira possui algum tipo de deficiência. Dos $14,5 \%$ de brasileiros, 4,1\% possuem deficiência física (INSTITUTO BRASILEIRO DE GEOGRAFIA E ESTATÍ́STICA, 2000). Os dados da Organização Mundial de Saúde (OMS) divulgados em 2001, mostram que $30 \%$ das pessoas possuem deficiência por doenças em geral; os acidentes de trânsito equivalem a 5,5\% das causas. Boa parte desses deficientes dependem da cadeira de rodas para se locomoverem. Muitos têm uma vida ativa, trabalham e estudam e, por isso, precisam se movimentar pelas cidades. Mas será que os municípios brasileiros, principalmente os grandes centros urbanos, estão preparados para proporcionar o bem estar desses cidadãos?

Segundo Antoneli (2003), a cadeira de rodas é um equipamento de auxílio ao deslocamento, e está entre uma das tecnologias assistivas utilizadas por pessoas que apresentam a impossibilidade, temporária ou definitiva, de deslocar-se utilizando os membros inferiores. Para ter acesso a esse equipamento, torna-se necessária a prescrição de um profissional habilitado no assunto, orientando ao tipo de cadeira e as e adaptações necessárias para a melhor acomodação do paciente. Os aspectos sociais e ambientais em que esta cadeira será utilizada irá impactar no tipo de cadeira e quais adaptações serão necessárias acrescentar à prescrição do equipamento.

Sob esse contexto, o presente estudo busca fazer uma investigaçao sobre o uso da cadeira de rodas para atividades do cotidiano, uma vez que a mesma é considerada como sendo parte do usuário, e com isso verificar os seus aspectos formais, funcionais e ergonômicos. Tomando por base alguns dos princípios do Design Universal e de Produto como: uso simples e intuitivo; informação de fácil percepção; baixo esforço físico e; dimensão e espaço para aproximação e uso. A proposta principal que rege essa pesquisa é projetar de forma criativa e operacional, de modo a oferecer um melhor conforto e acessibilidade ao seu usuário, um modelo de cadeira de rodas apropriado à prática comuns do diaa-dia.

Desde a década de 1970, quando foi promulgada a Declaração dos Direitos das Pessoas Deficientes, a sociedade vem buscando avanços na inclusão de pessoas com algum tipo de deficiência. A acessibilidade e o poder de ir e vir é um direito garantido por lei a todo e qualquer brasileiro seja ele deficiente ou não, pensando assim, busca-se formas de evitar que a sociedade se torne um ambiente hostil e inacessível para os portadores de deficiência.

De acordo com dados do IBGE obtidos com o censo de 2000, existem em todo o país 1.000.000 (um milhão) de brasileiros com deficiência física. A falta 
de atenção para com esta parte da população (bastante significativa) é visível na falta de manutenção em subsistemas de acessibilidade e até sua inexistência - outro fator a ser considerado é a exclusão social, é visível que o modo de encarar a deficiência está ligado ao processo histórico de desenvolvimento da sociedade. Na Idade Média, por exemplo, as pessoas com deficiência eram isoladas e asiladas do convívio em sociedade.

Os principais problemas que os cadeirantes enfrentam em seu cotidiano são: obstáculos para locomoção em vias públicas e até mesmo em áreas como: empresas, restaurantes e etc.; falta de conforto ao sentar; falta de higiene dos membros durante a locomoção e o visual do objeto que é estigmatizado.

A acessibilidade das pessoas portadoras de deficiência ou com mobilidade reduzida, mediante a supressão de barreiras e de obstáculos nas vias e espaços públicos, no mobiliário urbano, na construção e reforma de edifícios e nos meios de transporte e de comunicação, é garantida por lei de acordo com o artigo primeiro da lei 10.098. No entanto, há falta de manutenção nos subsistemas arquiteturais de adaptação e em muitos lugares esses subsistemas são inexistentes. Há obstruções desses subsistemas por parte dos transeuntes da cidade.

Outro fator a ser destacado é a associação da utilização de cadeiras de roda a invalidez, isolamento e incapacidade. O material e a estrutura dos produtos atuais são deficientes e a também existe a falta de um sistema de propulsão adequado.

Uma vez que o Design Universal como abordagem ergonômica busca ser ferramenta ativa para a solução dos problemas da maioria dos usuários, vê-se a necessidade de intervir no desenvolvimento de cadeiras de rodas para uso diário no intuito de facilitar e reduzir os constrangimentos vividos pelo portador de necessidades especiais.

O presente estudo busca apontar e detectar sugestões preliminares que contribuirão para um processo de intervenção no desenvolvimento das cadeiras de rodas para uso diário no intuito de facilitar e reduzir constrangimentos nas atividades desenvolvidas pelo usuário.

\section{MATERIAIS E MÉTODOS}

A pesquisa em seu parâmetro macro tem abordagem quantitativa e qualitativa, seguindo o método de intervenção ergonomizadora (MORAES; 
MONT'ALVÃO, 2003). Os resultados apresentados foram obtidos na etapa da Apreciação Ergonômica, através de registros fotográficos, análises comportamentais com usuários reais e aplicação de questionários.

A pesquisa foi desenvolvida entre março e dezembro de 2010, na cidade de Manaus - as análises e registros fotográficos que resultaram nos dados apresentados foram feitas no centro da cidade e os questionários, aplicados a usuários de cadeira de rodas, vinculados a Associação dos Deficientes Físicos do Amazonas - ADEFA.

\section{REFERENCIAL TEÓRICO}

\section{Cadeiras de rodas}

Segundo Lobach (2001), objetos de uso são ideias materializadas com a finalidade de eliminar as tensões provocadas pelas necessidades. A eliminação das tensões ocorre durante o processo de uso, quando o usuário desfruta das funções do objeto. Produtos de uso constituem uma parte importante da estrutura econômica de uma sociedade. Os objetos de uso são um retrato das condições de uma sociedade.

O mesmo autor citado ainda diz que, os produtos industriais são objetos destinados a cobrir determinadas necessidades e são produzidos de forma idêntica para um grande número de pessoas. A lógica dos produtos industriais consiste em que, quando produzidos, devam proporcionar - pela sua venda um lucro. Além disto, a natureza do produto deve garantir que seu uso possa efetivamente satisfazer as necessidades do usuário, já que este é o único motivo que o induz a despender algum dinheiro na sua compra.

A verdadeira tarefa do designer industrial é a configuração de produtos de uso, que, na maioria das vezes, têm uma vida útil maior que a dos produtos de consumo. Já se sabe que os produtos de uso em algum momento também se extinguem, isto é, tornam-se inutilizáveis. Este período de tempo é, na maioria das vezes, suficientemente longo para se estabelecer uma ligação pessoal entre o usuário e o produto. Somente ao final do ciclo de uso se chega à extinção do produto.

Alguns produtos, como placas de sinalização em ruas, não têm uma relação direta com o usuário. Quanto mais distante estiver um usuário de possuir ou utilizar um produto, maior é sua indiferença em relação ao mesmo. O extremo oposto é o uso pessoal dos produtos. Na psicologia se fala da relação com o 
objeto na constituição das relações individuais do homem com as coisas; o produto industrial estabelece uma relação psíquica durante o processo de uso.

A intensidade das relações entre o usuário e o produto industrial é também fator decisivo que o designer industrial deve considerar, superando as pressões exercidas pelos fatores econômicos.

Um produto de uso, uma vez criado, sempre pode satisfazer a determinadas necessidades através do processo de uso. Por exemplo, a eliminação dos pêlos da barba pelo uso de um barbeador elétrico. Durante este processo se experimentam as funções do produto, um dos aspectos da relação entre usuário e produto.

Ao falarmos em produtos para o uso individual, significa que se trata de produtos industriais usados exclusivamente por uma determinada pessoa. Daí resulta uma relação especialmente forte entre pessoa e objeto. No caso, o produto significa muito para o usuário. $\mathrm{O}$ uso de produtos pessoais provoca uma relação contínua e estreita entre o usuário e o produto, desencadeando um processo de identificação, em que o usuário se adapta ao produto formando uma unidade, e em que este se torna parte daquele. Isto nem sempre é consciente para o usuário, mas para o público fica prontamente identificável um deles na ausência do outro.

As características a serem incluídas no produto devem ser escolhidas a partir do estudo do comportamento do usuário e da percepção humana. Estes aspectos variam pouco para a maioria dos usuários. Como exemplo, podemos citar a capacidade de pega da mão do homem ou a faculdade do olhar humano, que pode reconhecer uma letra à distância, mesmo que pequena.

Para o fabricante, seria conveniente produzir apenas um modelo padronizado do produto. Contudo, isso restringiria as vendas, porque as preferências individuais variam bastante. Para ampliar o mercado, é necessário diversificar o desenho dos produtos para atender à diversidade de desejos dos consumidores.

Cadeiras de rodas são sistemas composto basicamente por uma cadeira disposta em um par de rodas. É utilizada como dispositivo de locomoção para portadores de deficiência ou que tenham alguma mobilidade física. Basicamente dividem-se em duas categorias: manuais e eletrônica, ambas podem ser movidas manualmente pelo usuário ou empurradas por alguém. Fatores como o dimensional do encosto e do assento de acordo com as medidas antropométricas são indispensáveis para o bom desenvolvimento projetual de tal sistema. 


\section{Aspectos ergonômicos aplicados às atividades em cadeiras de rodas}

\section{Manejos}

Segundo lida (2001), o manejo fino é executado com as pontas dos dedos, caracterizando-se pela precisão, velocidade e pouca aplicação de força. No manejo grosseiro, por sua vez, os dedos têm a função de prender, mantendo-se relativamente estáticos, enquanto os punhos e braços realizam o movimento. Em geral exige mais força, mas é menos preciso.

\section{Aplicação de forças}

As forças humanas são resultados de contrações musculares. Algumas forças dependem de apenas músculos, enquanto outras exigem uma contração coordenada de diversos músculos, principalmente se envolver combinações complexas de movimentos, como tração e rotação simultâneas. Para grandes esforços deve-se utilizar a musculatura das pernas, pois possui mais resistência. lida (2001) destaca também:

- Precisão - Os movimentos de maior precisão são realizados com a ponta dos dedos;

- Ritmo - Os movimentos devem ser suaves e possuir um ritmo constante, sem acelerações bruscas ou rápidas, pois exigem maiores contrações musculares;

- Movimentos retos - Os movimentos são mais dificeis de executar, pois exigem integração nos diversos movimentos do corpo;

- Terminações - movimentos acompanhados de tarefa visual devem ser terminados com posicionamento mecânico.

Sanderson e Sommer (1995) foram os primeiros a investigar as características do padrão de condução durante a propulsão da cadeira de rodas. Dois diferentes estilos de condução foram observados e definidos como circulares e condução de bombeamento. Cada usuário de cadeira de rodas manual adapta-se a um padrão de propulsão, ou seja, a trajetória realizada pelos membros superiores durante a propulsão. Existem quatro tipos de formas de acionamento de cadeira de rodas: semicírculo, laço, looping duplo e arco: 
Figura 1 - Tipos de propulsão
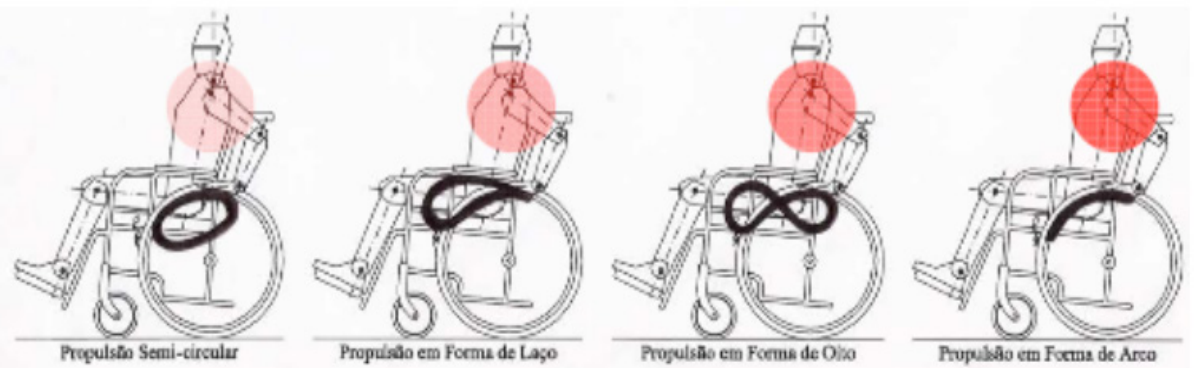

Fonte: Carriel (2010)

\section{Deficiência física}

O Censo 2000, (IBGE) indicou que no Brasil, existem 24,6 milhões de pessoas com deficiência. Esses dados representam e dizem que, 14,5\% da população brasileira possuem algum tipo de deficiência física. Os dados do IBGE indicam que a proporção de pessoas deficientes aumenta com a idade: crianças de até 14 anos representam 4,3\% dos deficientes; este número aumenta para $54 \%$ quando falamos em pessoas idade superior aos 65 anos.

Segundo a mesma fonte, a expectativa de vida apresenta um crescimento constante indicando um número proporcionalmente alto de idosos. No ano 2000 a população de idosos ultrapassava o número de 16 milhões. Em 20 anos, deverá ser de 32 milhões, número que colocará o Brasil como o sexto em população idosa no mundo. Abaixo, tabelas quantitativas de pessoas com deficiência por regiões do Brasil:

Tabela 1 - Região Norte

\begin{tabular}{|l|l|l|l|l|l|l|}
\hline \multicolumn{6}{|l|}{ Estados do Brasil e respectivas porcentagens de deficiência } \\
\hline Região Norte & Pará & Acre & Roraima & Amapá & Tocantins & Rondônia \\
\hline Amazonas & $17,8 \%$ & $13,5 \%$ & $\mathbf{1 1 , 6} \%$ & $11,7 \%$ & $15,4 \%$ & $15,5 \%$ \\
\hline
\end{tabular}

Fonte: IBGE (2000).

Tabela 2 - Região Nordeste

\begin{tabular}{|c|c|c|c|c|c|c|c|c|}
\hline \multicolumn{9}{|c|}{ Estados do Brasil e respectivas porcentagens de deficiência } \\
\hline \multicolumn{9}{|c|}{ Região Nordeste } \\
\hline Maranhão & Piauí & Ceará & Bahia & Sergipe & Rio Grande & Alagoas & Paraíba & Pernambuco \\
\hline $16,8 \%$ & $18 \%$ & $16,8 \%$ & $15,3 \%$ & 14,8 & $\begin{array}{l}\text { do Norte } \\
19,5 \%\end{array}$ & $15,4 \%$ & $19 \%$ & $17,2 \%$ \\
\hline
\end{tabular}

Fonte: IBGE (2000). 
Tabela 3 - Região Centro-Oeste

\begin{tabular}{|c|c|c|}
\hline \multicolumn{3}{|c|}{ Estados do Brasil e respectivas porcentagens de deficiência } \\
\hline \multicolumn{3}{|c|}{ Região Centro-Oeste } \\
\hline Mato Grosso & Goiás & Mato Grosso do Sul \\
$14,5 \%$ & $13,3 \%$ & $14,3 \%$ \\
\hline
\end{tabular}

Fonte: IBGE (2000).

Tabela 4 - Região Sudeste

\begin{tabular}{|c|c|c|c|}
\hline \multicolumn{4}{|c|}{ Estados do Brasil e respectivas porcentagens de deficiência } \\
\hline \multicolumn{4}{|c|}{ Região Sudeste } \\
\hline São Paulo & Minas Gerais & Rio de Janeiro & Espírito Santo \\
$11,2 \%$ & $14,5 \%$ & $14,8 \%$ & $15,3 \%$ \\
\hline
\end{tabular}

Fonte: IBGE (2000).

Tabela 5 - Região Sul

\begin{tabular}{|c|c|c|}
\hline \multicolumn{3}{|c|}{ Estados do Brasil e respectivas porcentagens de deficiência } \\
\hline \multicolumn{3}{|c|}{ Região Sul } \\
\hline Paraná & Santa Catarina & Rio Grande do Sul \\
$13,3 \%$ & $14,6 \%$ & $15,1 \%$ \\
\hline
\end{tabular}

Fonte: IBGE (2000).

\section{Ergonomia Emocional}

A Ergonomia emocional quebra o paradigma de "como avaliar o usuário" e utiliza-se do "como o usuário avalia". O objetivo é aperfeiçoar a interação homem-tecnologia, através da individualização e da experiência prazerosa.

A Carga Emocional está ligada ao sentimento, reflete como se sente o indivíduo ao lidar com seu trabalho. É extremamente subjetiva, pois cada indivíduo reage de maneira diferente a cada situação.

Segundo Marina Pezzini (2013), o design deve comunicar mais, ser mais estético, significar mais, fornecer uma experiência de uso completa, além de ser funcional e usável, deve estabelecer uma conexão com o usuário, conexão esta que gere afeto.

Os cinco princípios fundamentais da experiência emocional com produtos são: interação fluida, lembrança de memória afetiva, significado simbólicosocial; compartilhamento de valores morais e interação física prazerosa. 


\section{Ambiente de Estudo}

O estudo analisará as atividades diárias de deficientes físicos em ambientes com acessos a áreas comuns da cidade de Manaus, podendo citar: vias públicas e terminais de ônibus do centro da cidade e estrutura física da Associação de Deficientes Físicos do Amazonas - ADEFA. Abaixo mapa indicando os pontos onde foram realizados análises e registros fotográficos:

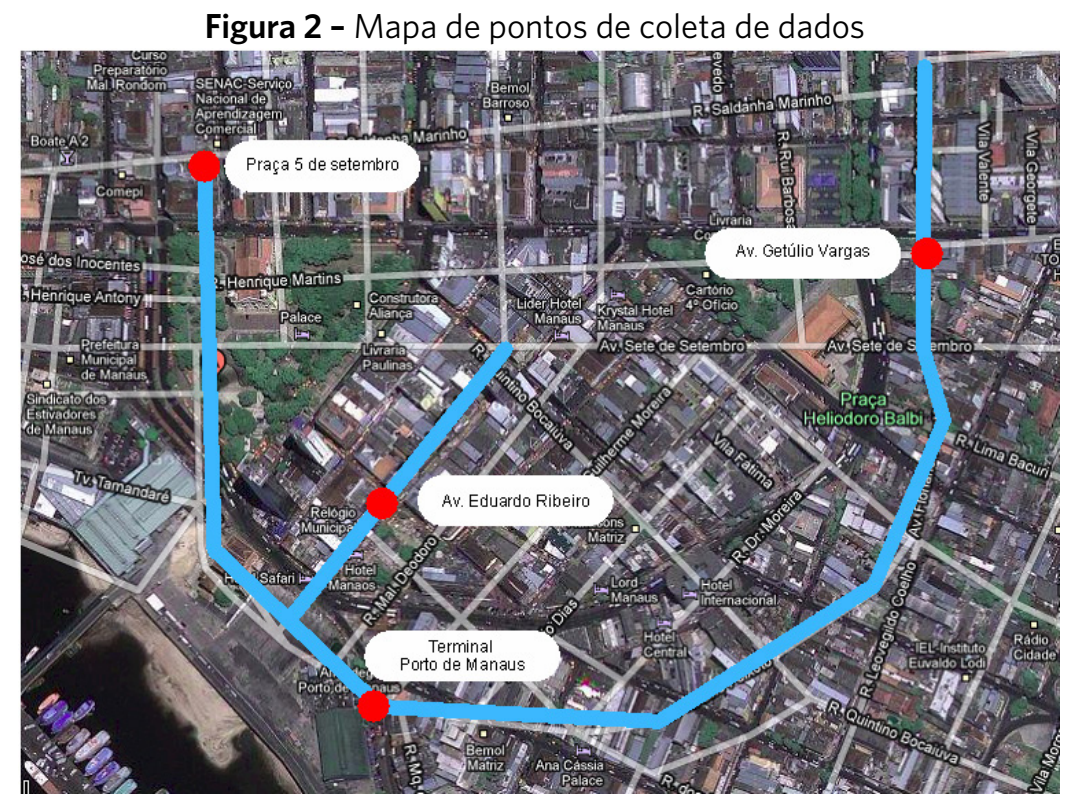

Fonte: Google Mapas, com adaptação (2013).

Em seguida, fachada da ADEFA, local onde foram realizadas simulações de uso, aplicação de questionários e coletas de dados com profissionais e envolvidos com estudos voltados a deficiência física:

Figura 3 - Fachada da Associação dos Deficientes Físicos do Amazonas

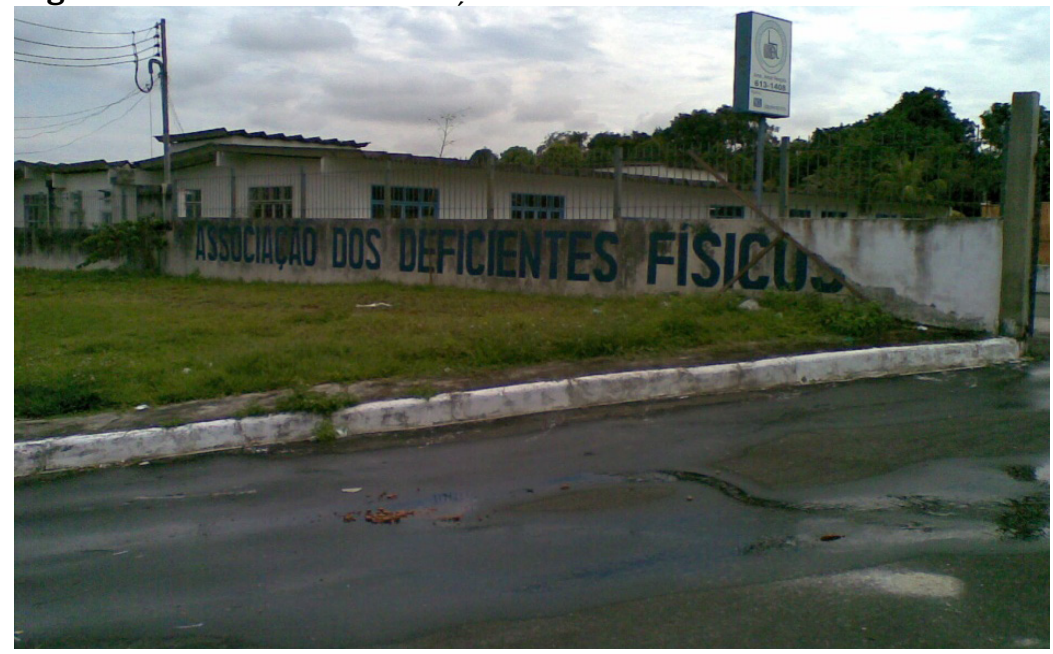

Fonte: Autor 


\section{Objeto de estudo}

A Cadeira de rodas éum objeto de uso individual utilizado como instrumento de locomoção por deficientes físicos em suas atividades cotidianas. O modelo estudado tem a denominação: 1009 trata-se da cadeira de rodas clássica fabricada pela empresa Baxmann e Jaguaribe com as seguintes especificações: capacidade máxima de peso - $80 \mathrm{~kg}$, feita em aço com assento e encosto em nylon ou courvim, rodas nylon 24", revestimento com pintura epoxy, disponível apenas na cor cinza. Em Manaus, a cadeira de rodas é encontrada pelo valor de $R \$ 350,00$ (trezentos e cinqüenta reais).

Figura 4 - Modelo 1009 (objeto de estudo)

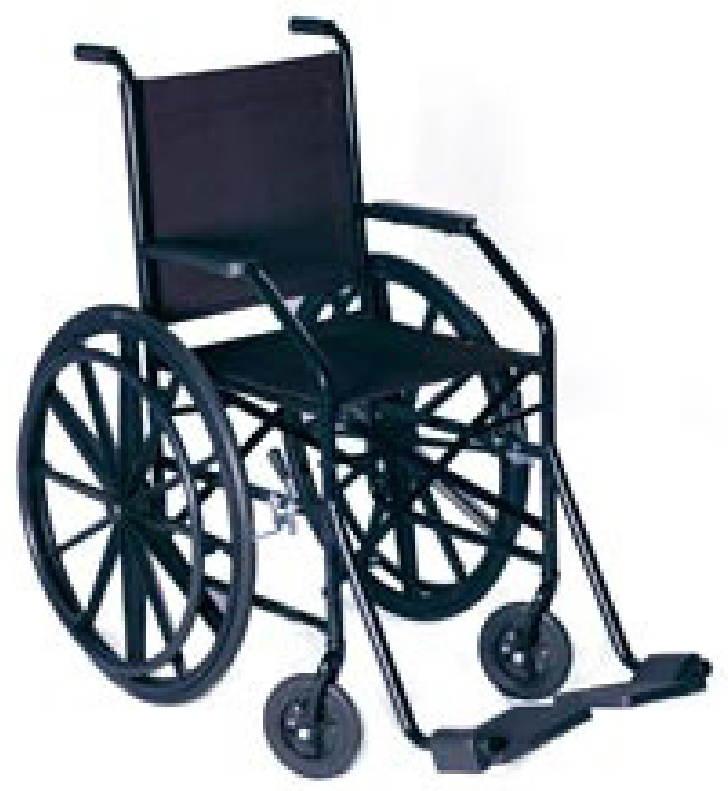

Fonte: Baxmannjaguaribe (2013).

\section{Sujeitos}

Os dados da Organização Mundial de Saúde (OMS) divulgados em 2001 mostram que $30 \%$ das pessoas possuem deficiência por doenças em geral. Visando atingir um grupo maior, serão acompanhados portadores de deficiência física causada por lesionamento (paraplegia, paralisia cerebral, West e seqüela de mielomeningocele) na faixa etária entre 17 e 40 anos ligados a Associação de Deficientes Físicos do Amazonas - ADEFA.

\section{Procedimentos: técnicas aplicadas}

O processo de design pode-se desenvolver de forma complexa, dividi-lo 
em fases facilita a compreensão e a execução do mesmo. Cada uma dessas fases é composta de técnicas específicas que contribuem no entendimento do sistema-produto estudado.

Problemas detectados na execução de atividades diárias em cadeiras de rodas

Abaixo, tabela com os problemas detectados e suas respectivas categorias:

Tabela 6 - Taxionomia dos problemas

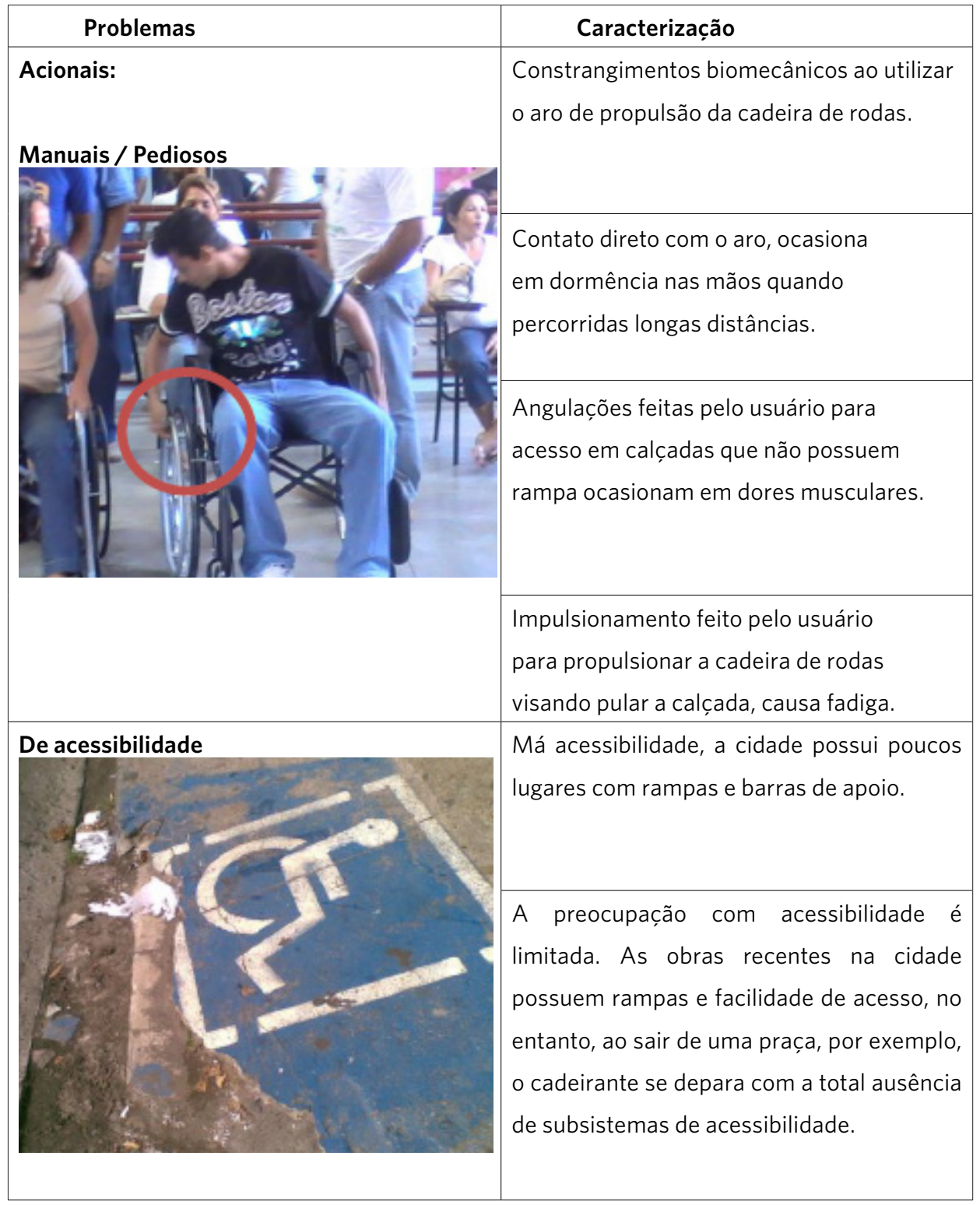




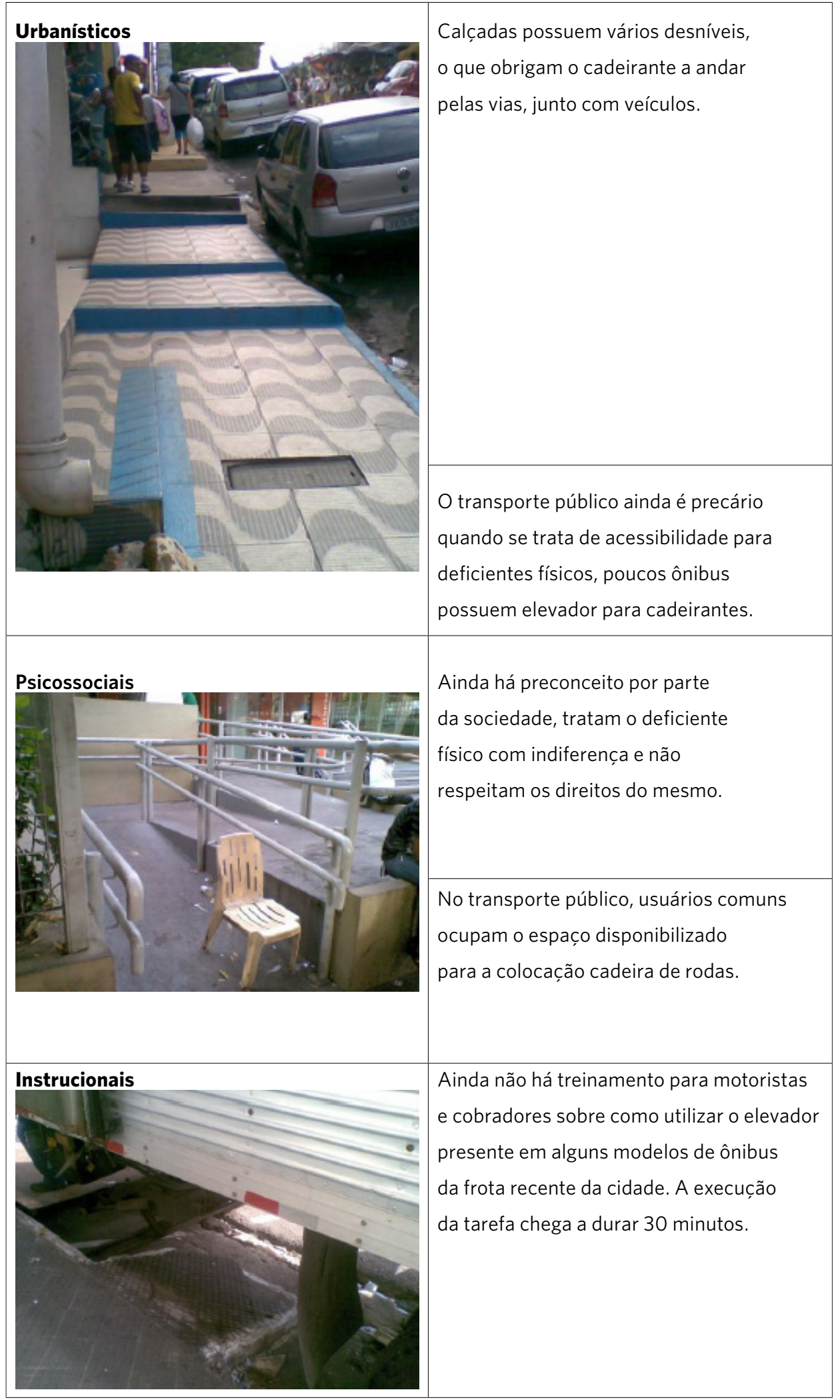




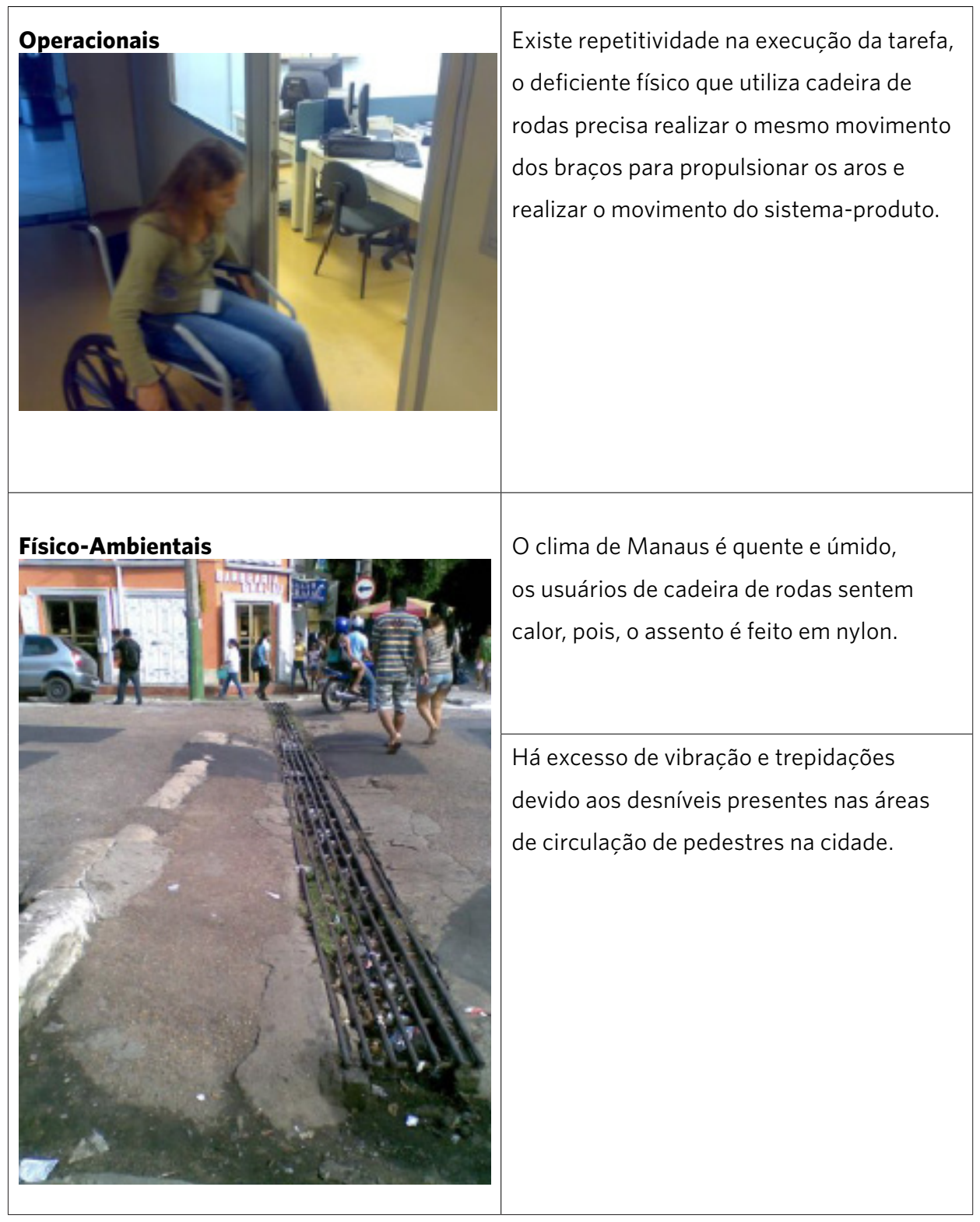

Fonte: Própria, 2013.

\section{OUTROS DADOS RELEVANTES}

\section{Usuários de cadeiras de rodas}

A deficiência física em sua maioria é causada por lesionamentos, podendo citar como principais: paraplegia, paralisia cerebral, west e sequela de mielomeningocele.

Para todos os usuários de cadeiras de rodas, Manaus não possui infraestrutura adequada para acessibilidade total aos deficientes físicos que utilizam 
cadeira de rodas.

Dentre as atividades diárias mais comuns executadas predominou-se: ir a praça, ir a igreja, deslocar-se para as instituições de apoio e fazer compras.

$80 \%$ dos entrevistados utilizam transporte público, os mesmos, acusam o descaso da população para com os deficientes, ocupando o espaço pertencente a colocação da cadeira de rodas e agindo com indiferença.

Os motoristas não possuem treinamento para elevação do usuário deficiente físico ao ônibus, a atividade é executada em média em 30 minutos.

O principal motivo para utilização da cadeira de rodas clássica está ligado ao baixo custo de aquisição. As principais reclamações sobre o modelo estão ligadas ao desconforto e calor causado pelo tecido do assento (nylon) e os usuários reclamam que as rodas originais da cadeira de rodas não amortecem o impacto do sistema-produto com o solo, causando dores na coluna e nas costas.

Os representantes comerciais que disponibilizam a venda de cadeiras de rodas indicam que os fabricantes mais próximos e que fornecem os produtos para as lojas de Manaus, estão localizados em São Paulo.

\section{Quanto ao ambiente}

Levantaram-se os dados físicos do ambiente como: temperatura, vibrações e estrutura urbanística. Para isso utilizou-se de registros fotográficos nas áreas pré-definidas como ambiente de estudo no centro da cidade. A temperatura da cidade é algo mensurável, no entanto, há variações e oscilações assim, segundo o INMET-AM (Instituto de Metereologia do Amazonas) o clima é equatorial úmido, com temperatura média anual de $26,7^{\circ} \mathrm{C}$, variando entre $23,3^{\circ} \mathrm{C} \mathrm{C}$ e $31,4^{\circ} \mathrm{C}$. A umidade relativa do ar oscila na casa de $80 \%$ e a média de precipitação anual é de $2.286 \mathrm{~mm}$. A região possui duas estações distintas: a chuvosa (inverno), de Dezembro a Maio, período em que a temperatura mostra-se mais amena, com chuvas freqüentes; e a seca (verão ou menos chuvosa), de Junho a Novembro, época de sol intenso e temperatura elevada, em torno de $38^{\circ} \mathrm{C}$, chegando a atingir quase $40^{\circ} \mathrm{C}$, no mês de Setembro. Costumam ocorrer, durante todo o ano, fortes pancadas de chuva de pouca duração.

Os subsistemas de acessibilidade não possuem manutenção adequada, a destruição dos mesmos na maioria das vezes é causada por veículos que estacionam nas áreas indevidas. Os subsistemas existentes muitas vezes 
são bloqueados por veículos o que impedem a utilização dos mesmos pelos usuários de cadeira de rodas.

\section{Sugestões Preliminares}

De acordo com as análises feitas até então para compreensão do sistemaproduto estudado. Seguem as seguintes sugestões:

- Melhoria no processo de produção, visando aspectos estéticos mais agradáveis;

- Uso de cores, visando diminuir o visual estigmatizado;

- Agregar subsistema mecânico que facilite a passagem por áreas onde não existem subsistemas de acessibilidade;

- Aperfeiçoar aros de propulsão, buscando higienização da tarefa e conforto na pega;

- Buscar soluções ergonômicas e de materiais que proporcionem conforto ao sentar.

\section{CONSIDERAC̣̃̃ES FINAIS}

A acessibilidade é um direito garantido por lei, no entanto, muito ainda deve ser feito para que deficientes físicos possam realizar suas atividades sem constrangimentos de execução.

O trabalho visa contribuir de forma significativa para que essas atividades sejam realizadas, proporcionando conforto e segurança aos usuários. O projeto minimiza os problemas sofridos no cotidiano por parte do cadeirante em lugares que não há subsistemas de acessibilidade.

O design emocional é fator bastante presente na pesquisa e no resultado do projeto, o preconceito com a imagem do deficiente físico ainda é fator marcante na sociedade. Os estudos e pesquisas voltados a acessibilidade e design de produtos de uso direto por deficientes físicos ainda necessita de maior atenção e promoção na sociedade. 


\section{REFERÊNCIAS}

ANTONELI, M. Prescrição de cadeira de rodas. In: TEIXEIRA, E. et al. (Ed.). Terapia ocupacional na reabilitação física. São Paulo: Roca, 2003.

BAXMANNJAGUARIBE. Ortopedia Jaguaribe. Disponível em: <http:// www.baxmannjaguaribe.com.br/>. Acesso em: 12 ago. 2013.

CARRIEL, I. R. R.; PASCHOARELLI, L. C. Teste de usabilidade em cadeira de rodas. In: CONGRESSO INTERNACIONAL DE ERGONOMIA E USABILIDADE DE INTERFACES HUMANO-TECNOLOGIA: PRODUTO, INFORMAÇÕES, AMBIENTE CONSTRUÍDO E TRANSPORTE, 10., 2010, Rio de Janeiro. Anais... Rio de Janeiro: PUC, 2010.

GOOGLE Mapas. Disponível em: <https://www.google.com.br/>. Acesso em: 19 abr. 2013.

IBGE. Censo demográfico 2000. Rio de Janeiro, 2000. p. 1-178.

IIDA, I. Ergonomia: projeto e produção. São Paulo: E. Blucher, 2001.

LOBACH, B. Design industrial: bases para a configuração dos produtos industriais. São Paulo: E. Blucher, 2001.

MORAES, A.; MONT'ALVÃO, C. Ergonomia: conceitos e aplicações. 3. ed. Rio de Janeiro: iUsEr, 2003.

PEZZINI, M. Design emocional: curso: design, disciplina: Ergonomia 3 - UFSC. Notas de Aula. Slides. 2013. Disponível em: <http://www. slideshare.net/marinapzn/apostila-de-design-2013>. Acesso em: 19 abr. 2013.

SANDERSON, O. J.; SOMMER, H. J. Kinematic features of wheelchair propulsion. Journal of Biomechanics, New York, v. 18, n. 6: p. 423-429, 1995.

VAN DER LINDEN, J. Ergonomia e design: prazer, conforto e risco no uso dos produtos. Porto Alegre: UniRitter, 2007. 